\title{
Role of water and moisture in diapause development (A review)
}

\author{
Ivo HODEK \\ Institute of Entomology, Academy of Sciences, Branišovska 31, CZ-370 05 České Budějovice, Czech Republic; \\ e-mail: hodek@entu.cas.cz
}

Key words. Diapause development, horotelic vs. tachytelic processes, diapause intensity, post-diapause morphogenesis, water, moisture, temperature, photoperiod

\begin{abstract}
While observational studies led to the assumption that water or moisture (W/M) is a prerequisite for diapause development, the experimental research indicates rather the opposite: usually W/M is needed as late as for the post-diapause resumption of morphogenesis. Recent examples for this type of regulation of dormancy are given: Eggs of the tettigoniid Stictophaula armata, eggs of the grasshopper Oedaleus senegalensis, adults of the bruchid Bruchidius atrolineatus, adults of the endomychid Stenotarsus subtilis (= S. rotundus). In the late diapause of the noctuid Busseola fusca and in eggs of the chrysomelid Homichloda barkeri, moisture is assumed to be the diapause terminating cue. Fall in temperature is assumed decisive for termination of pupal diapause in the saturniid Schausiella santarosensis, although the effect of intense rain after a long dry period has not yet been excluded. Effects of intense changes in environmental conditions and of gradual decrease in diapause intensity with time have often been neglected.
\end{abstract}

\section{INTRODUCTION}

Most studies of seasonal ecology of insects focus on photoperiod and temperature as principal regulating cues (Tauber et al., 1986; Danks, 1987). Although particularly photoperiod has an essential role due to the high reliability of its precise repetition year after year, moisture should not be underestimated - as was rightly indicated by Tauber et al. (1998). Detailed experimental protocols for the study of moisture were suggested in the mentioned forum paper, but not many such experiments have been performed since then. A serious survey can nevertheless be based on several detailed and precise experimental studies and a quite long series of observations.

There is an obvious causal relation between the regrowth of vegetation, produced by rain after a period of drought, and the resumption of the active phase of insect life. The principal function of diapause is to assure synchronization of these two phenomena. These facts represent the basis for a widely accepted assumption that moisture or water $(\mathrm{M} / \mathrm{W})$ is the factor regulating the development of such diapauses that are in some way related to alternation of periods of drought and high humidity. It appears that the impact of moisture on dia- pause development is not so simple. It is, in fact, so complex that often the interpretation of findings remains ambiguous.

Andrewartha's (1952) remark, that it is difficult to unravel the true causal relationships between water and diapause, is certainly true. According to his opinion "the absorption of water is rarely if ever the primary stimulus which initiates diapause development".

\section{NEGATIVE VS. POSITIVE INFLUENCE OF WATER/RAIN}

Increasing relative humidity and precipitation was recorded as a seasonal signal for annual vertical migration of arthropods to trees in flooded plains of central Amazonia (Adis \& Junk, 2002). The ascent to tree trunks occurs 3-4 months before forest inundation. The reproduction of arthropods (that are usually univoltine), such as tiger beetles (Pentacomia egregia), is postponed to the terrestrial phase after inundation (Table 1).

Not only flooding, but also very high humidity can endanger the development of descendants and delay oviposition to the post-rain season (Table 1, below). The females of a Mexican bruchid beetle, Acanthoscelides obtectus, spend the wet period between April and

TABLE 1. Examples of multiple relations of insects to water.

\begin{tabular}{|c|c|c|c|c|}
\hline signal & & & examples & reference \\
\hline \multirow[t]{4}{*}{+} & SYNCHRONISATION & & & \\
\hline & with host-plant regrowth & after winter diap. & Leptinotarsa 10-lineata (Chrysomelidae) & Tauber et al. (1994) \\
\hline & & after dry season & Hypolimnas bolina (Nymphalidae) & Kemp (2001) \\
\hline & with growth of fungi & “ & Stenotarsus rotundus (Endomychidae) & Tanaka et al. (1987a, b) \\
\hline \multirow[t]{3}{*}{-} & ESCAPE & & & \\
\hline & from water & inundation regions & Pentacomia egregia (Cicindellidae) & Adis \& Junk (2002) \\
\hline & from moisture & seed eating larvae & Acanthoscelides obtectus (Bruchidae) & Hodek et al. (1981) \\
\hline
\end{tabular}




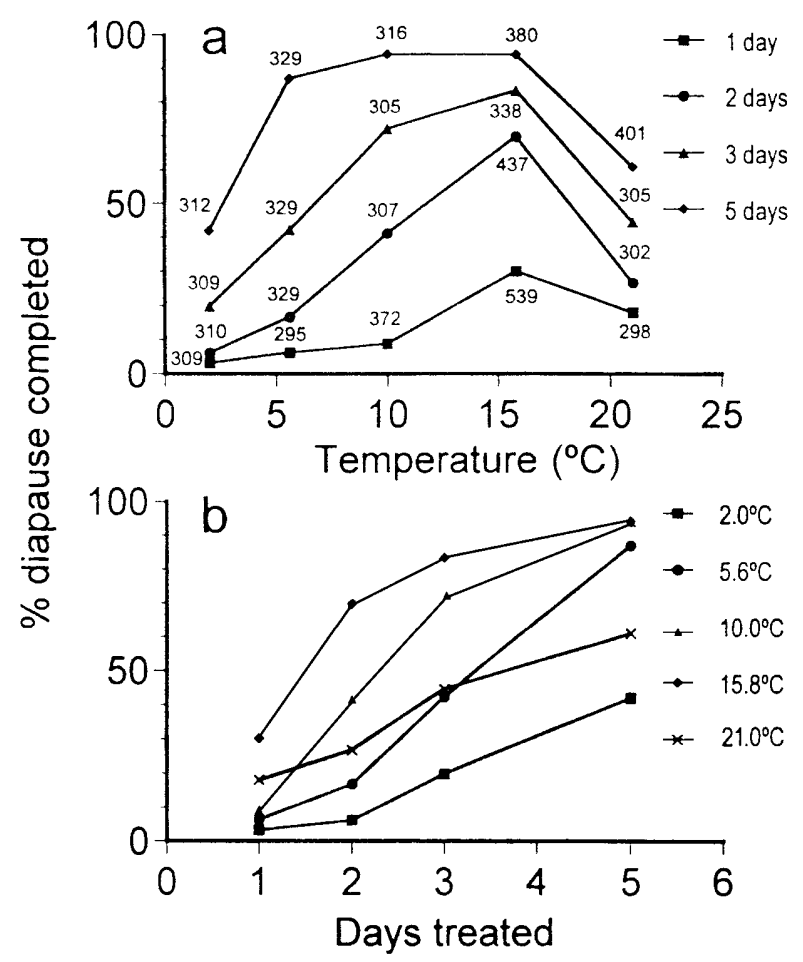

Fig. 1. Effect of temperature on completion of the summer diapause of Delia antiqua. (Before experiments, diapause was induced at $25^{\circ} \mathrm{C}, 16 \mathrm{~L}: 8 \mathrm{D}$.) a - percentage of diapause completion obtained when individuals were exposed to five temperatures, for time intervals indicated on the right margin. Values near the symbols indicate the numbers of puparia used; $b$ effect of five temperatures, indicated on the right margin, on completion of diapause in respect to the duration of treatment. (Ishikawa et al., 2000)

November in reproductive diapause in rolled dead leaves hanging from plants, and postpone the oviposition (midNovember to late December), i.e. to the period when precipitation is below $50 \mathrm{~mm}$ per month (Hodek et al., 1981). The larvae developing inside bean seeds may thus be saved from the highly probable dying in decaying beans. A contrasting example of synchronization of reproduction with high humidity can be mentioned. The reproduction in the tropical endomychid beetle, Stenotarsus subtilis (= S. rotundus; Roubik \& Skelley, 2001) occurs in May, i.e. the first month of the wet season (Tanaka et al., 1987a, b; Tanaka, 2000; Table 1, above; see also the last chapter). It feeds most probably on fungi like the other beetles from this family, but a direct evidence is still missing. The difference in food requirements of larvae could explain the contrasting timing of reproduction in relation to rainy seasons in the above two species of beetles.

\section{EFFECT OF PHOTOPERIOD AND TEMPERATURE IN SUMMER DIAPAUSE}

Before proceeding to cases where a more or less active role of $\mathrm{M} / \mathrm{W}$ in diapause termination was recorded (or at least supposed) it should be stressed that in many summer diapauses no decisive effect was found. Diapause termination has often been reported to be governed rather by decrease in photophase and temperature (Masaki, 1980; Tauber et al., 1986; Danks, 1987; Hodek, 1996, 2002).

A recent example of summer diapause completed by low temperature is Delia antiqua (Ishikawa et al., 2000; Fig. 1). Sometimes, however, diapause in tropical insects is terminated by several days exposure to high temperature $\left(25^{\circ} \mathrm{C}\right)$, as was reported in parasites of Drosophila (Carton \& Claret, 1982) or in sarcophagids (Denlinger, 1986). These relations were already discussed in the classic reviews of Masaki (1980) and Denlinger (1986). In Table 2 some recent examples are given. It should, however, be indicated that in most cases the effect of $\mathrm{M} / \mathrm{W}$ was not excluded.

In a detailed study on Stenotarsus subtilis $(=S$. rotundus) (Tanaka et al., $1987 \mathrm{a}$, b; Tanaka, 2000; see the last chapter), where the resumption of activity and dispersal from dormancy sites were recorded at the beginning of rainy period, the role of photoperiod was not only observed in the field, but also proved by experiments as decisive. An experimental proof that the photoperiod and not moisture is the decisive factor for diapause development was given for two chrysomelids, Chrysolina hyperici and C. quadrigemina (Schops et al., 1996; Fig. 2). It also was proved by experiments in prepupae of the Mediterranean arctiid moth Cymbalophora pudica (Kostal \& Hodek, 1997) that photoperiod is the decisive factor for diapause development. In this moth the action of $\mathrm{M} / \mathrm{W}$ and temperature was excluded.

TABLE 2. Species in which summer diapause is terminated by other factor than water/moisture.

\section{Larva}

Elcysma westwoodii

Anagrus takeyanus, Kyoto popul. short days

short days, low $\mathrm{T}^{\circ}$

short days, low $\mathrm{T}^{\circ}$, also the intrinsic ovarian development short days, low $\mathrm{T}^{\circ}$

short days, low $\mathrm{T}^{\circ}$

short days, $\mathrm{T}^{\circ}$ neutral

short days

short days
Gomi \& Takeda, 1992

Tsukuda, 1999

\section{Adult}

Leptocarabus kumagaii

Heteronympha merope

Chelymorpha alternans

Hypera postica

Chrysolina hyperici

Chrysolina quadrigemina

Topp, 1986

Sota, 1987

James, 1988

Pullin \& Knight, 1992

Elden, 1995

Schops et al., 1996

Schops et al., 1996 


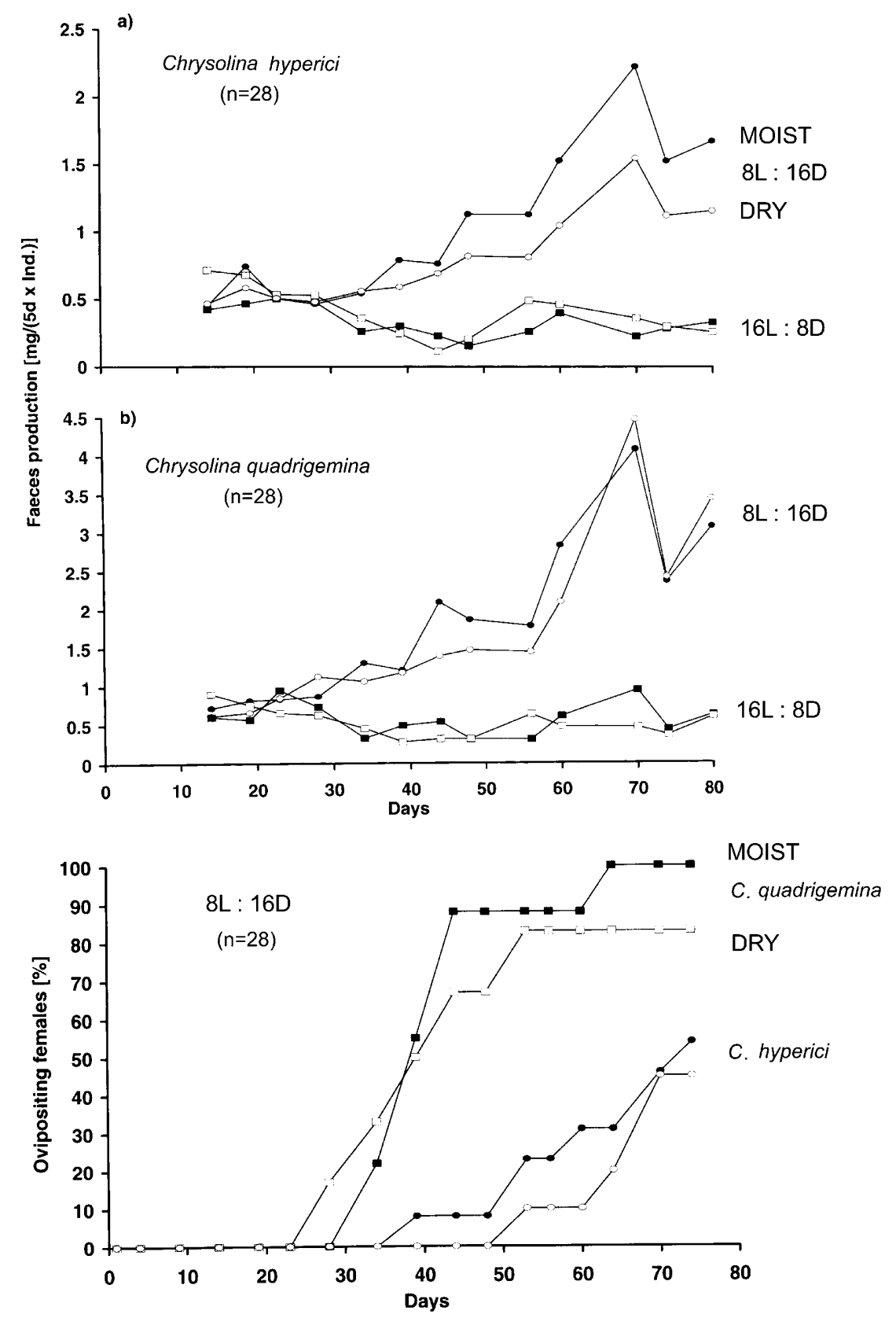

Fig. 2. Termination of summer diapause in females of two Chrysolina spp. under contrasting photoperiod and humidity conditions, recorded by production of faeces $(\mathrm{a}, \mathrm{b})$ and cumulative proportion of ovipositing females (c). (Schops et al., 1996)

\section{ROLE OF MOIST AND DRY PERIODS IN DIAPAUSE DEVELOPMENT}

Tropical borers have been the most popular example of diapause terminated by rains.

In spite of several studies, the role of water in termination of larval diapause in several species of African borers remained only partially understood until the series of clever experiments on the noctuid Busseola fusca performed in Kenya by Okuda (1988, 1990, 1991). Larvae of this sorghum stem borer spend 6 to 8 months in diapause in dry stalks and pupate after the onset of rains in spring. Okuda (1991) found that water stimulates pupation only in late diapause and he proved by experiments that a previous exposure to drought is a prerequisite for the stimu- latory effect of wetting (Figs $3 \& 4$ ). Diapause development evidently proceeds at dry conditions, while wet conditions are then needed for the resumption of development and pupation. Okuda (1990) was also able to find out that the stimulation is produced rather by a continuous contact with moist surroundings than through drinking. When diapausing larvae were provided with water by means of a pipet no pupation was recorded when they did not become wet (Okuda, 1990). The drinking larvae did not pupate although their constant weight indicates that they had higher water content than the wet larvae (Fig. 5).

Similar positive effect of a dry period was found in Thailand in diapausing eggs of a tettigoniid Stictophaula 


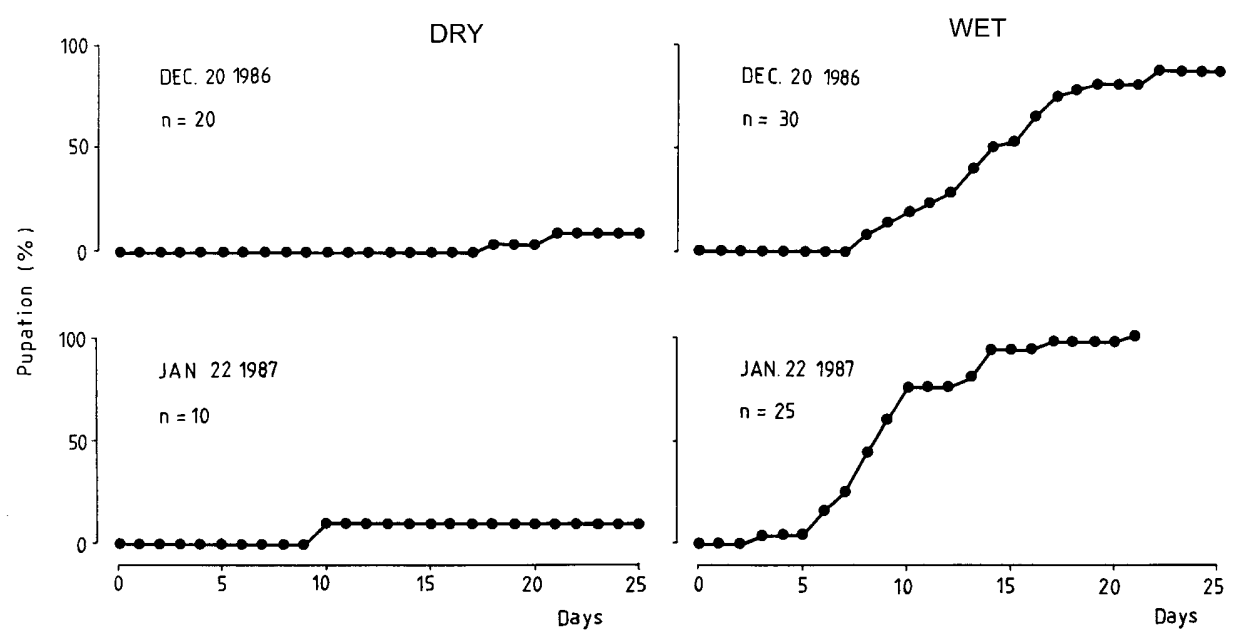

Fig. 3. Pupation of larvae of Busseola fusca, diapausing from July and transferred in December and January to laboratory dry and wet conditions. (Okuda, 1988)

armata by Ingrisch (1996). While the apparently postdiapause "dry" eggs (after 6 months $=180$ day storage) hatched early after wetting (the peak of hatching was after about $4 \mathrm{wk}$ ), the constantly moist eggs had a bimodal hatching, with only about $30 \%$ of (probably non-diapause) eggs hatched within 5 weeks. Hatching of the other $30 \%$ was delayed until about 200-300 days. The pre-hatch period of the second mode of constantly moist eggs was thus longer than in the case of eggs that spent
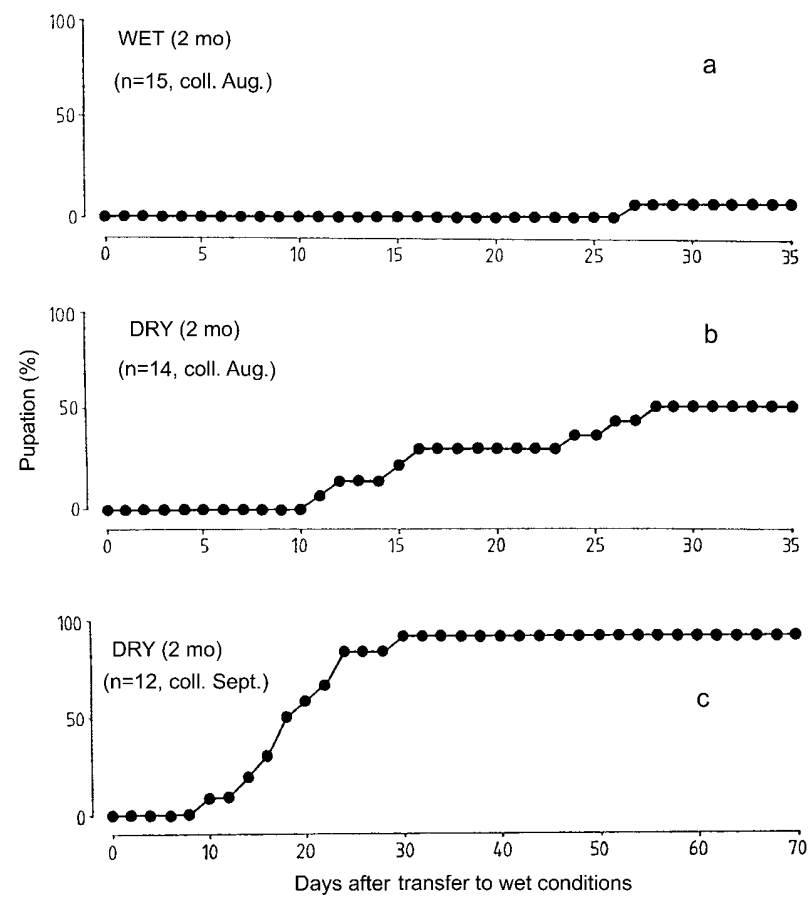

Fig. 4. Pupation of larvae of Busseola fusca, diapausing from July and transferred in August and September to laboratory wet conditions. Before the experiment the insects were always stored for 2 months; at either wet conditions (a), or at dry conditions $(b, c)$. (Larvae in the September sample lived one month longer in the field drought than the August sample.) (Okuda, 1991) about 180 days in low RH (Fig. 6). Moreover, in another experiment, Ingrisch (1996) achieved the same effect after only 2-3 months storage in $60 \% \mathrm{RH}$, as after 6 months.

The interpretation of these similar results by the two authors is not the same. While Okuda (1991) suggested that a tachytelic moist completion of diapause followed after a period of horotelic processes of diapause, Ingrisch (1996) assumed that a post-diapause hygric quiescence was terminated by water. He also suggested that "drought as a proximate factor for the elimination of diapause has been rarely discussed" and "could be more commonly
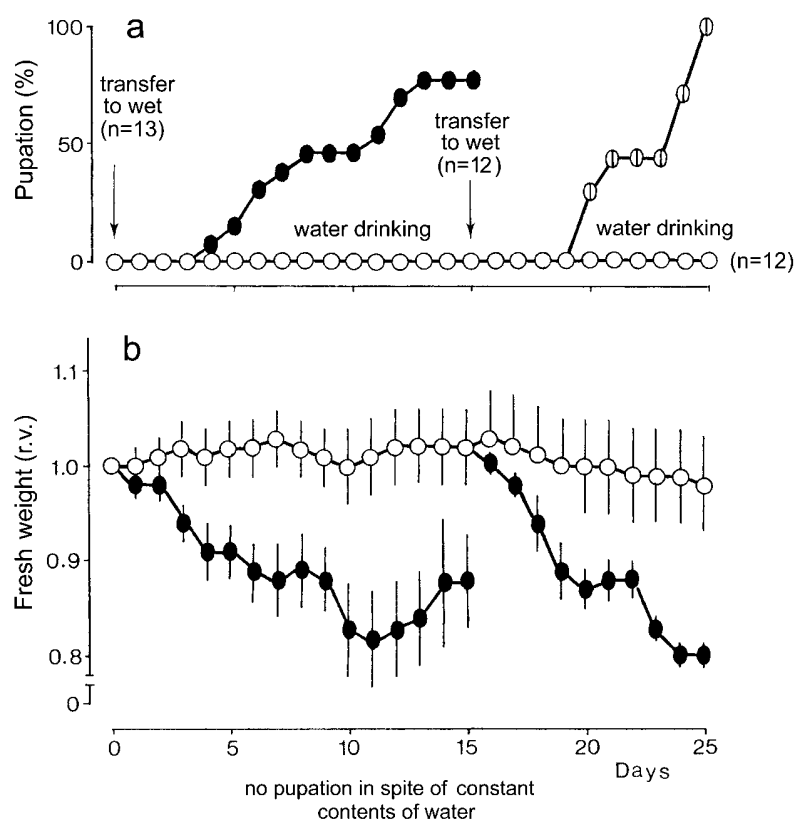

Fig. 5. a - pupation of larvae of Busseola fusca (diapausing from July, collected in mid January, $\mathrm{n}=37$ ), when drinking water without contact to moist environment $(O)$ vs. in contact with moist environment (wetted, $\bullet$ ); $b$ - fresh weight of larvae under the two experimental procedures as indicated in (a). (Okuda, 1990) 

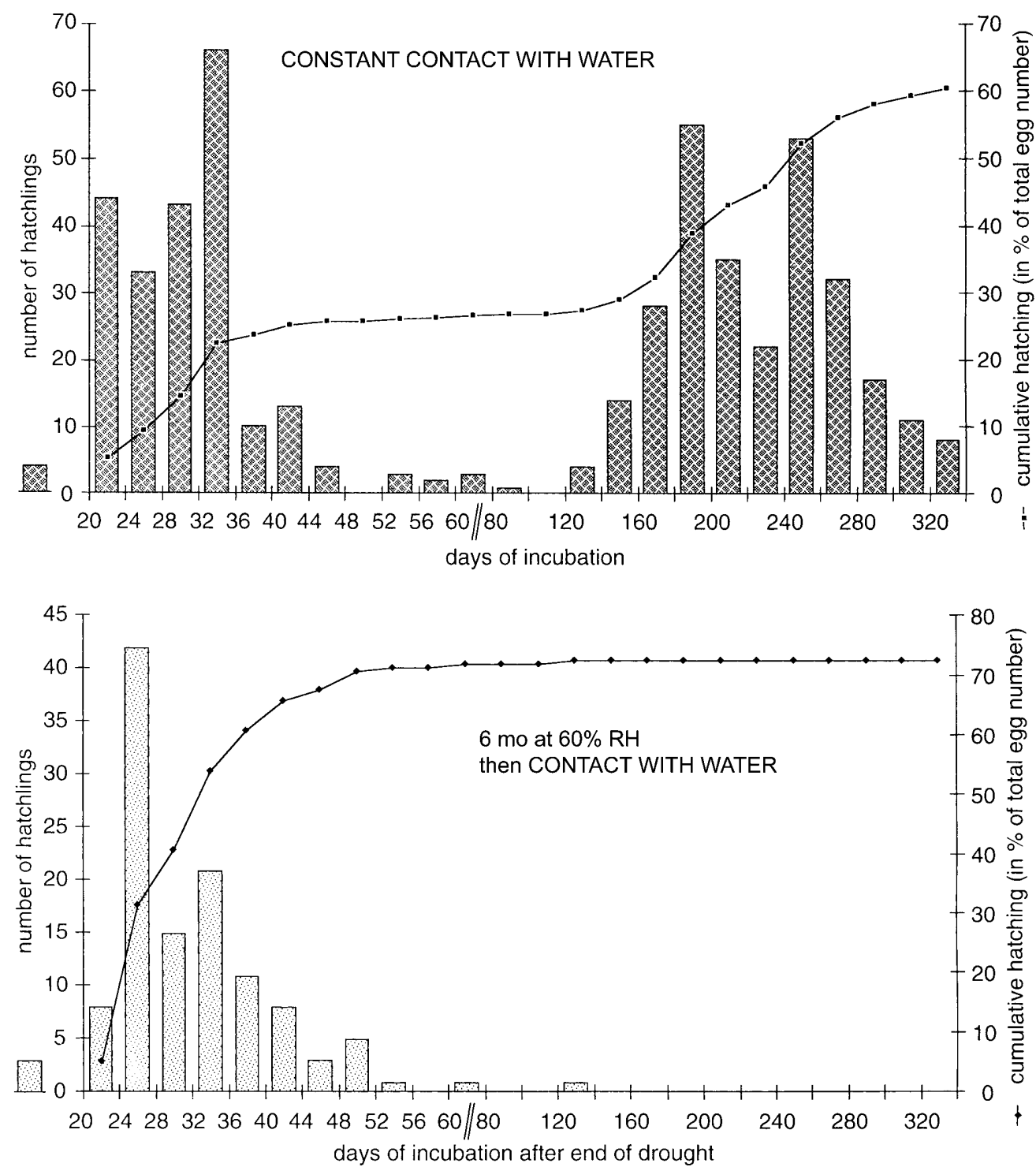

Fig. 6. Hatch of diapause eggs in Stictophaula armata; above - when in constant contact with water; below - placed into contact with water after 6 month of $60 \%$ rel. humidity (this represents drought for S. armata eggs). (Ingrisch, 1996)

detected in areas with a pronounced dry season, if it was looked for".

The importance of dry periods - although in a different sense - was clearly shown also in egg diapause of the African chrysomelid Homichloda barkeri introduced to Australia (Nahrung \& Merritt, 1999). Significantly higher hatch rate was recorded under the regime of alternated wetting and drying than under constant moisture. A similar proportion of larvae hatched from eggs wetted daily and from those wetted every 23rd day. In the latter group hatching lasted more than six times longer (Fig. 7). It was evident that each subsequent wetting stimulated development of a further proportion of embryos. The constant period of 12-14 days between wetting and eclosion indicates that at each wetting, embryos within the developing cohort begun development at the same stage of embryogenesis. In Homichloda, diapause development was thus completed within only 2 to 4 weeks through daily wetting and the delay in the cohort with less frequent wetting events was due only to longer intervals between wetting events. For the same total hatching rate, however, much less wetting events were needed (9) compared to the daily wetting regime (27). Two factors had a complementary role: Wetting events and the passage of time. It may be suggested that horotelic processes of diapause development alternated with tachytelic activation events. The authors consider wetting events per se responsible for "breaking" diapause. They assume thus that diapause of Homichloda is in this aspect different from that of Diabrotica virgifera (Krysan, 1978) where moisture triggers development after a previous spontaneous diapause termination.

There are many cases similar to Diabrotica, in which the completed diapause development is followed by a quiescence due to low moisture. The post-diapause morphogenesis is not resumed until water content is replenished to/above a critical level. Thus, e.g., the larvae of the wheat blossom midges, Contarinia tritici and Sitodiplosis mosellana need high soil moisture for pupation after the 


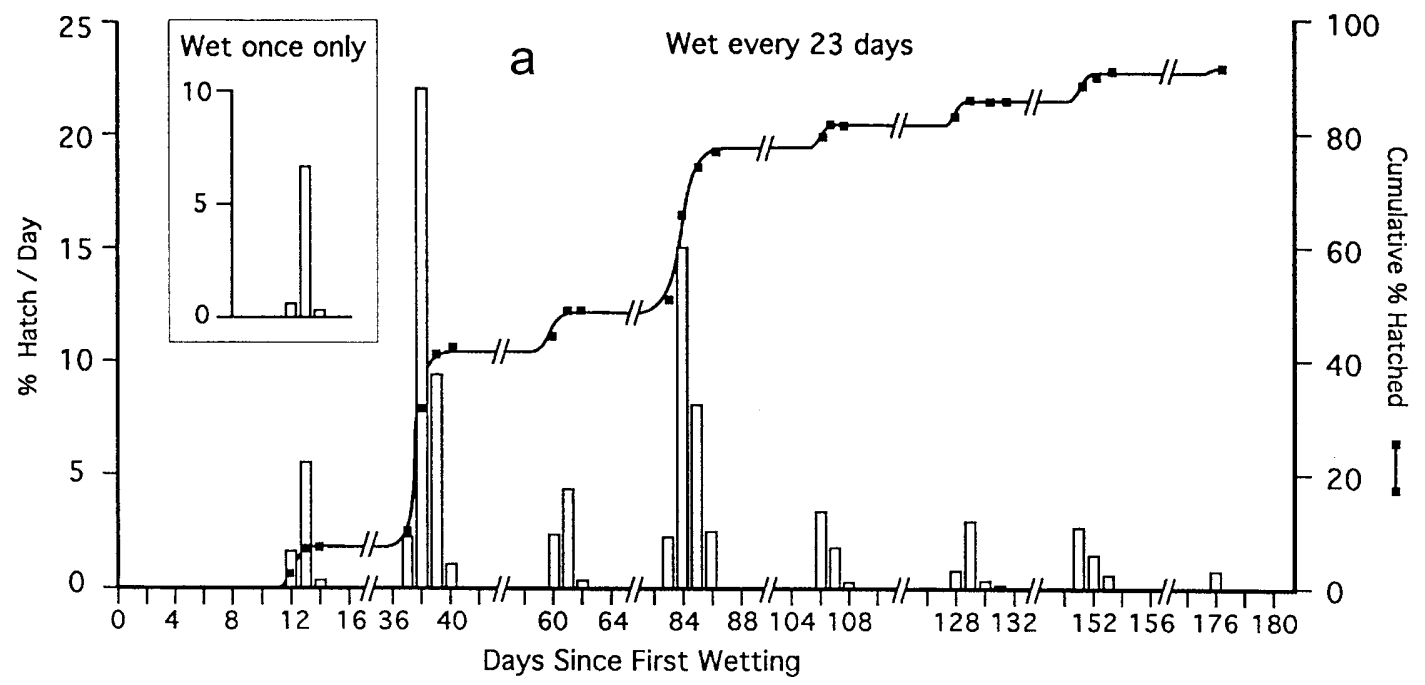

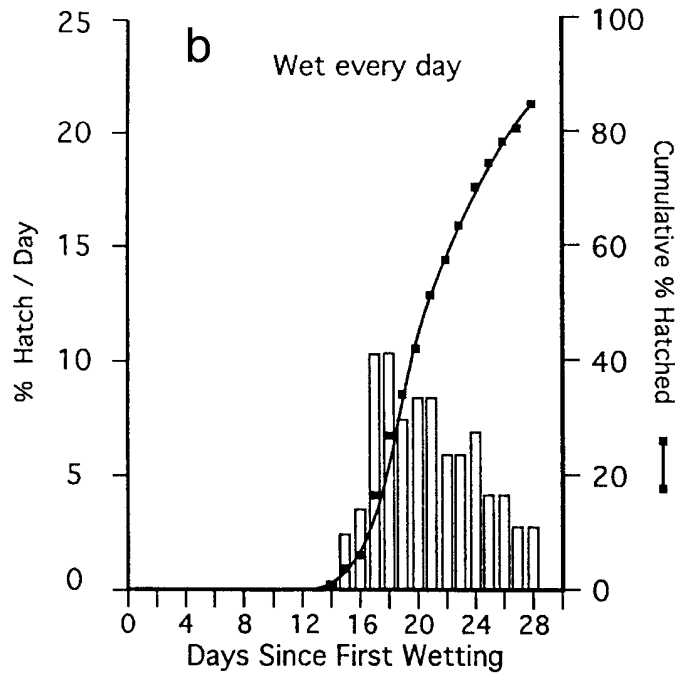

temperature regulated diapause development (Basedow, 1977).

Another example of such a sequence of low moisture quiescence after diapause completion was reported as one of the possible developmental pathways in eggs of the Australian plague locust, Chortoicetes terminifera (Acrididae). The development of the so called "second quiescent stage", that is morphologically indistinguishable from the previous diapause stage, cannot start without replenishing about $10 \%$ of moisture lost during diapause (Wardhaugh, 1988). Diapause development lasts $30-60$ days at $10-15^{\circ} \mathrm{C}$ and hatching occurs in warmth in spring. Also Gehrken \& Doumbia (1996) concluded from detailed observations in Mali that the eggs of the grasshopper Oedaleus senegalensis complete diapause development after 7-8 months and remain thereafter dormant in "a state of postdiapause quiescence until the return of moist conditions".

In addition to other environmental cues (mainly short days) also high humidity (70-80\%) was needed for termination of reproductive diapause in the Sahelian bruchid Bruchidius atrolineatus (Lenga et al., 1993; Glitho et al., 1996). Vitellogenesis was considered here as a criterion

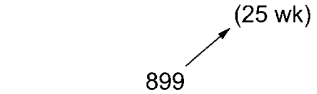

Total number hatched 835

Fig. 7. Hatch of diapause eggs of Homichloda barkeri after three wetting procedures; inlet in (a) wet only once. a - wet every 23 rd day; $b$ - wet every day. (Nahrung \& Merritt, 1999)

of diapause termination. Most probably the dormancy scenario could be similar in the bruchid adults and in the cases mentioned earlier, eggs of orthopterans or larvae of the stem borer: Also here diapause development was completed during the long dry season and the cues of the rainy season (high humidity and pollen of host plants) switched on the post-diapause development.

Action of several environmental factors is apparently combined in the already classical model of tropical diapause, the adult dormancy of the endomychid beetle Stenotarsus subtilis $(=$ S. rotundus) in Panama (Tanaka, 2000). This beetle spends a long, up to 10 months (6 months of the wet season and 4 months of the dry season) dormancy within large aggregations (Fig. 8). While the breeding sites and food requirements of the beetle probably still remain unknown, experiments with dormant beetles reveal the role of environmental cues, namely photoperiod, in diapause development, and moisture in the resumption of post-diapause development. Although at the low latitude of Panama $\left(9^{\circ} \mathrm{N}\right)$ the difference between the longest and shortest day is only one hour, the increasing photophase appears to stimulate from March the early weak growth of CA, primary oocytes and flight 


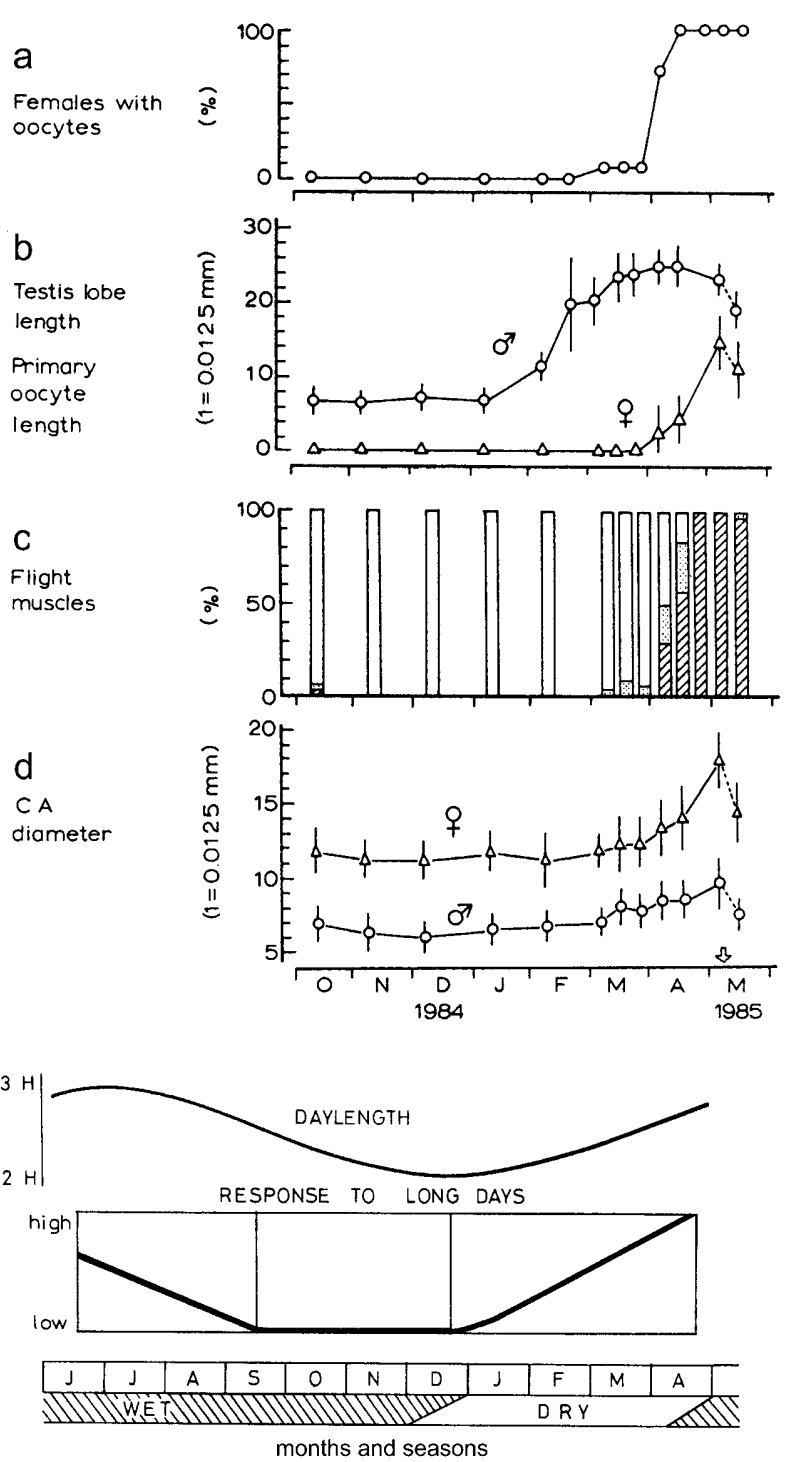

Fig. 8. Changes in gonads (a, b), flight muscles (c) and corpora allata (d) in diapausing adults of Stenotarsus rotundus. Below - photoperiod and humidity conditions at the Panaman site, with the assumed sensitivity to photoperiod. (Tanaka et al.,1987a, b; Tanaka, 2000)

muscles. Similar to many species, it is difficult in $S$. subtilis $(=S$. rotundus) to pin-point when diapause development is completed and the post-diapause quiescence begins. Mating and dispersal coincide with the onset of rains. Usually a short early period of rain during the rainy season is sufficient for triggering dispersal, but in some years dispersal may be bimodal (Tanaka, 2000). Probably the beetles with still less developed flight muscles "wait" for the next rain. Effects of exposures of 2 months to contrasting relative humidities of $100 \mathrm{vs.} 75 \%$ confirmed the existence of stimulation by the higher humidity on early development of several organs: Ovaries, male accessory glands and flight muscles (Denlinger, 1994; Tanaka, 2000). It seems that moisture stimulates post- diapause development in only those beetles that had already completed diapause development before the start of experimental humidity exposures in mid-February. Another sample was collected more than 2 months earlier, at the
SEASONS IN A COSTA RICAN TROPICAL DRY FOREST

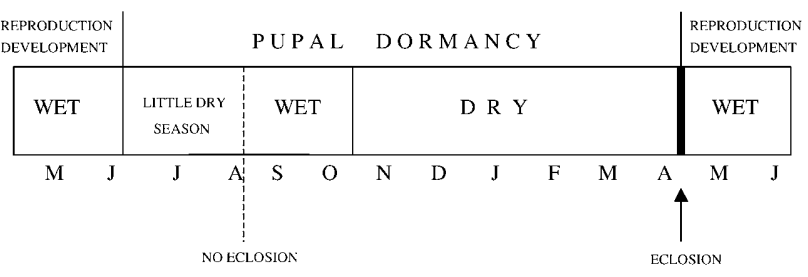

Fig. 9. Life cycle of Schausiella santarosensis and environmental conditions in the Costa Rican site. (After Janzen, 1987)

end of wet season, in early December (Tanaka et al., $1987 \mathrm{a}, \mathrm{b}$ ) and exposed for the same period of 2 months to the identical high humidity. A comparison of the development of organs between these two samples indicates that an important progress of diapause development occurred already during 10 weeks of dry season.

The humidity exposures did not affect the size of testes in $S$. subtilis (=S. rotundus). This parameter is not important for monitoring its diapause, because reproductive diapause in coleopteran males involves the accessory glands rather than testes, as was shown in coccinellids (Hodek \& Ceryngier, 2000).

In a detailed study on seasonality of Lepidoptera in a Costa Rican tropical dry forest, Janzen (1987) is suspicious to the widely accepted assumption that rains are the cue for pupal eclosion. He suggests on the contrary that the cue is the "temperature and/or its changes, rather than the actual moisture brought by rainfall". Thus, e.g., an experimental exposure to moisture does not re-initiate development in the pupae of the saturniid Schausiella santarosensis. The about 2-4 months old pupae remain dormant also through the "little wet season" (before the subsequent 6 month dry season) but the pupae eclose at the beginning of the second wet season, when they are about 8 months old. A dramatic drop in temperature at the beginning of the second rainy season occurs about a week before "really soaking" rains arrive (Fig. 9). Also several other saturniids were observed to eclose after a series of exceptionally cool days with nocturnal lows of $17-18^{\circ} \mathrm{C}$ (Janzen, 1987). Janzen's assumption sounds quite plausible. However, two other possibilities remain to be excluded. (1) In the 2-4 month old pupae the horotelic processes of diapause development are, most probably, not yet progressed enough, i.e. diapause development is not completed. (2) The effect of contrast in physical conditions (heavy rains after the long dry period) can play an important role, similar to the effect of contrasts in photoperiod or temperature, suggested in temperate diapauses (Hodek, 1978, 1983, pp. 19-24, 2002; Zaslavsky, 1978).

\section{CONCLUSION}

It can be concluded from detailed experimental studies that the assumption of positive direct effects of W/M on the processes of diapause development is mostly erroneous - when based merely on observations. On the contrary, diapause development is often completed spontaneously during a dry period and is followed by a 
TABLE 3. Species in which moisture was reported as an environmental cue for diapause termination; mostly for post-diapause resumption of activity/development, but also diapause development.

\section{Egg}

Allonemobius fasciatus

Chortoicetes terminifera

Trirhabda geminata

Oedaleus senegalensis

Stictophaula armata

Homichloda barkeri

Deois flavopicta

\section{Larva}

Contarinia tritici

Sitodiplosis mosellana

Contarinia sorghicola

Busseola fusca

".

Coniesta ignefusalis

\section{Pupa}

Schausiella santarosensis

Manduca dilucida

Pharate adult in cocoon

Crioceris sp.

\section{Adult}

Agabus disintegratus

Stenotarsus rotundus

Zygogramma bicolorata

Bruchidius atrolineatus

Leptinotarsa decemlineata

Dicladispa gestroi

Hypolimnas bolina

\author{
wetting \\ rain \\ wetting \\ $1 \%$ soil moisture is satisf. \\ water contact \\ wetting \\ water
}

rain, soil moisture

rain, soil moisture

rain, soil moisture

water contact

intensive rain

continuous rain

rain? $\mathrm{T}^{\circ}$ decrease, rain rain

submersion (30s)

\section{inundation}

$100 \%$ R.H.

monsoon rains

increase to $80 \%$ R.H.

rain, soil moisture

rain

rain
Tanaka, 1987

Wardhaugh, 1988

Bethke \& Redak, 1996

Gehrken \& Doumbia, 1996

Ingrisch, 1996

Nahrung \& Merritt, 1999

Pires et al., 2000

Basedow, 1977

Basedow, 1977

Forrester, 1987

Okuda, 1988, 1990

Moyal, 1998

Tanzubil et al., 2002

Janzen, 1987

Janzen, 1987*

Witt \& Edwards, 2002

Garcia \& Hagen, 1987

Tanaka et al., 1987a, b

Jayanth \& Bali, 1993

Lenga et al., 1993

Tauber et al., 1994

Delucchi, 2001

*more lepidopteran species discussed in this paper.

hygric quiescence. It is during this second part of dormancy, in early post-diapause, when the loss of water is replenished and the resumption of morphogenic development is enabled (Tables $3 \& 4$ ).

In discussions on the role of various factors in completion of diapause, three factors are mostly invoked, photo- period, temperature and water or moisture (W/M), while two further factors are almost always neglected, a necessary passage of time and the effect of contrast. In many insect species the horotelic processes of diapause development cannot be substituted by activation too early; diapause development simply needs to be completed

TABLE 4. Assumptions on the role of moisture/water in diapause termination.

\section{MOISTURE NEEDED for POST-DIAPAUSE DEVELOPMENT}

Ando, 1972 - Atrachya menetriesi - egg

Krysan, 1978 - Diabrotica virgifera - egg (moisture allowing development to continue after diapause terminates spontaneously)

Tanaka, 1987 - Allonemobius fasciatus - egg (termination of summer diapause independent of water absorption)

Forrester, 1987 - Contarinia sorghicola - larva - (rains no effect until diapause requirements .... satisfied)

Wardhaugh, 1988 - Chortoicetes terminifera - egg - (post-diapause $2^{\text {nd }}$ quiescent stage)

Gehrken \& Doumbia, 1996 - Oedaleus senegalensis - egg

Ingrisch, 1996 - Stictophaula armata - egg

Pires et al., 2000 - Deois flavopicta - egg - (water did not enhance the rate of diapause development)

\section{MOISTURE NEEDED for DIAPAUSE DEVELOPMENT}

Okuda, 1988, 1990 - Busseola fusca - larva - (only in late diapause)

Nahrung \& Merritt, 1999 - Homichloda barkeri - egg 
before the post-diapause development is resumed under influence of W/M (Janzen, 1987). It seems that a previous period of drought predisposes the insects to the effect of the increase in moisture.

The difficulty to discriminate easily between these two periods of dormancy leads some authors to avoid the problem by using the ambiguous term "termination" of diapause (to include both diapause development and postdiapause development) against which Tauber et al. (1986, 1998 ) and Danks (1987) rightly warned. When we misuse this term, we elude the challenge to understand how the two certainly different phases of dormancy - diapause vs. post-diapause quiescence are regulated. We should strive to elucidate this problem by well focussed experimental studies. The methodical viewpoint paper by Tauber et al. (1998) could help in planning such trials.

ACKNOWLEDGEMENTS. The study was partially funded by the grants GA CR 206/00/0946 of the Grant Agency of the Czech Republic, by the Project Z 500/7907 of the Academy of Sciences of the Czech Republic and ME 169/1998-2002 of the Ministry of Education of the Czech Republic.

\section{REFERENCES}

ADIS J. \& JUNK W.J. 2002: Terrestrial invertebrates inhabiting lowland river floodplains of Central Amazonia and Central Europe: a review. Freshw. Biol. 47: 711-731.

ANDo H. 1972: Egg diapause and water absorption in the false melon beetle, Atrachya menetriesi (Coleoptera: Chrysomelidae). Appl. Entomol. Zool. 7: 142-154.

AnDREwartha H.G. 1952: Diapause in relation to the ecology of insects. Biol. Rev. 27: 50-107.

BASEDow T. 1977: Der Einfluss von Temperatur und Niederschlagen auf Diapause und Phanologie der Weizengallmucken Contarinia tritici und Sitodiplosis mosellana (Dipt: Cecidomyidae). Zool. Jb. Syst. 104: 302-326.

BethKe J.A. \& RedaK R.A. 1996: Temperature and moisture effects on the success of egg hatch in Trirhabda geminata (Coleoptera: Chrysomelidae). Ann. Entomol. Soc. Am. 89: 661-666.

Carton Y. \& Claret J. 1982: Adaptive significance of a temperature induced diapause in a cosmopolitan parasitoid of Drosophila. Ecol. Entomol. 7: 239-247.

DANKs H.V. 1987: Insect Dormancy: an Ecological Perspective. Biol. Survey Canada, Natl. Mus. Nat. Sci., Ottawa, 439 pp.

Delucchi V. 2001: Biology and control of Dicladispa gestroi (Col.: Chrysomelidae). J. Appl. Entomol. 125: 493-500.

Denlinger D.L. 1986: Dormancy in tropical insects. Anmu. Rev. Entomol. 31: 239-264.

Denlinger D.L. 1994: The beetle tree. Am. Entomol. 1994: $168-171$

EldEN T.C. 1995: Effects of dormancy and photoperiod on alfalfa weevil (Coleoptera: Curculionidae) reproductive diapause. J. Entomol. Sci. 30: 481-488.

FORRESTER N.W. 1987: Diapause development in the sorghum midge, Contarinia sorghicola (Diptera: Cecidomyidae). Bull. Entomol. Res. 77: 581-587.

GARCIA R. \& HAGEN K.S. 1987: Summer dormancy in adult Agabus disintegratus (Coleoptera: Dytiscidae) in dried ponds in California. Ann. Entomol. Soc. Am. 80: 267-271.

Gehrken U. \& Doumbia Y.O. 1996: Diapause and quiescence in eggs of a tropical grasshopper Oedaleus senegalensis. $J$. Insect Physiol. 42: 483-491.
Glitho I.A., Lenga A., Pierre D. \& Huignard J. 1996: Changes in the responsiveness during two phases of diapause termination in Bruchidius atrolineatus (Coleoptera: Bruchidae) $J$. Insect Physiol. 42: 953-960.

GomI T. \& TAKEDA M. 1992: A quantitative photoperiodic response terminates summer diapause in the tailed zygaenid moth, Elcysma westwoodii. J. Insect Physiol. 38: 665-670.

HoDEK I. 1978: Role of temperature in diapause of Pyrrhocoris apterus (Heteroptera). Vest. Cs. Spol. Zool. 42: 172-187.

HODEK I. 1983: Role of environmental factors and endogenous mechanisms in the seasonality of reproduction in insects diapausing as adults. In: Brown V.K. \& Hodek I. (eds): Diapause and Life Cycle Strategies in Insects. Junk, The Hague, pp. 9-33.

HODEK I. 1996: Diapause development, diapause termination and the end of diapause. Point of view. Eur. J. Entomol. 93: 475-487.

Hodek I. 2002: Controversial aspects of diapause development. Point of view. Eur. J. Entomol. 99: 163-173.

Hodek I., Bonet A. \& Hodkova M. 1981: Some ecological factors affecting diapause in adults of Acanthoscelides obtectus (Col.: Bruchidae) from Mexican mountains. In: Labeyrie V. (ed.): The Ecology of Bruchids Attacking Legumes (Pulses). Junk, The Hague, pp. 43-55.

Hodek I. \& Cerrngier P. 2000: Sexual activity in Coccinellidae (Coleoptera): a review. Eur. J. Entomol. 97: 449-456.

INGRISCH S. 1996: Evidence of an embryonic diapause in a tropical Phaneropterinae (Insecta Ensifera Tettigonioidea). Tropic. Zool. 9: 431-439.

IshiKaWA Y., Yamashita T. \& Nomura M. 2000: Characteristics of summer diapause in the onion maggot, Delia antiqua (Diptera: Anthomyidae). J. Insect Physiol. 46: 161-167.

JAMES D.G. 1988: Aestivation and reproductive dormancy in adult Heteronympha merope merope (Lepidoptera: Nymphalidae). Aust. Entomol. Mag. 15: 67-72.

JANZEN D.H. 1987: How moths pass the dry season in a Costa Rican forest. Insect Sci. Appl. 8: 489-500.

JAYANTH K.P. \& BALI G. 1993: Diapause behaviour of Zygogramma bicolorata (Coleoptera: Chrysomelidae), a biological control agent for Parthenium hysterophorus (Asteraceae), in Bangalore, India. Bull. Entomol. Res. 83: 383-388.

KEMP D.J. 2001: Reproductive seasonality in the tropical butterfly Hypolimnas bolina (Lepidoptera: Nymphalidae) in northern Australia. J. Tropic. Ecol. 17: 483-494.

Kostal V. \& Hodek I. 1997: Photoperiodism and control of summer diapause in the Mediterranean tiger moth, Cymbalophora pudica (Lepidoptera: Arctiidae). J. Insect Physiol. 43: 767-777.

KRYSAN J.L. 1978: Diapause, quiescence, and moisture in the egg of the western corn rootworm, Diabrotica virgifera. $J$. Insect Physiol. 24: 535-540.

Lenga A., Glitho I. \& Huignard J. 1993: Interactions between photoperiod, relative humidity and host-plant cues on the reproductive diapause termination in Bruchidius atrolineatus (Coleoptera: Bruchidae). Invert. Repr. Dev. 24: 87-96.

MASAKI S. 1980: Summer diapause. Anmu. Rev. Entomol. 25: $1-25$.

MoYal P. 1998: Infestation patterns and parasitism of the maize stalk borer, Busseola fusca (Lepidoptera: Noctuidae), in the Ivory Coast. Afric. Entomol. 6: 289-296.

Natrung H.F. \& MerRitT D.J. 1999: Moisture is required for the termination of egg diapause in the chrysomelid beetle, Homichloda barkeri. Entomol. Exp. Appl. 93: 201-207. 
OKUDA T. 1988: Effect of artificial wetting and rainfall on the larval diapause of a stem borer, Busseola fusca in western Kenya. Entomol. Exp. Appl. 48: 263-267.

OKUDA T. 1990: Significance of water contact as a factor terminating larval diapause in a stem borer, Busseola fusca. Entomol. Exp. Appl. 57: 151-155.

OKUDA T. 1991: Enhancement of diapause development in a stem borer Busseola fusca (Lep.: Noctuidae) by dry conditions. Appl. Entomol. Zool. 26: 49-53.

Pires C.S.S., Sưm E.R., Fontes E.M.G., Tauber C.A. \& Taurber M.J. 2000: Dry-season embryonic dormancy in Deois flavopicta (Homoptera: Cercopidae): roles of temperature and moisture in nature. Envir. Entomol. 29: 714-720.

PULLIN A.S. \& KNIGHT T.M. 1992: Induction and termination of reproductive diapause in a neotropical beetle, Chelymorpha alternans (Coleoptera: Chrysomelidae). J. Zool. 227: 509-516.

RoubIK D.W. \& Skelley P.E. 2001: Stenotarsus subtilis Arrow, the aggregating fungus beetle of Barro Colorado Island Nature Monument, Panama (Coleoptera: Endomychidae). Col. Bull. 55: 249-263.

Schops K., Syrett P. \& Emberson R.M. 1996: Summer diapause in Chrysolina hyperici and C. quadrigemina (Coleoptera: Chrysomelidae) in relation to biological control of St John's wort, Hypericum perforatum (Clusiaceae). Bull. Entomol. Res. 86: 591-597.

SотA T. 1987: Effects of temperature and photoperiod on the larval hibernation and adult estivation of Leptocarabus kumagaii (Coleoptera, Carabidae). Appl. Entomol. Zool. 22: 617-623.

TANAKA S. 1987: Changing responses to temperature and moisture of diapausing and developing eggs of Allonemobius fasciatus (Orthoptera: Gryllidae). J. Insect Physiol. 33: 635-641.

TANAKA S. 2000: The role of moisture in the control of diapause, mating and aggregation in a tropical insect. Entomol. Sci. 3: $147-155$.

Tanaka S., Denlinger D.L. \& Wolda H. 1987a: Daylength and humidity as environmental cues for diapause termination in a tropical beetle. Physiol. Entomol. 12: 213-224.
Tanaka S., Wolda H. \& Denlinger D.L. 1987b: Seasonality and its physiological regulation in three Neotropical insect taxa from Barro Colorado Island, Panama. Insect Sci. Appl. 8: 507-514.

Tanzubil P.B., Mensah G.W.K. \& McCaffery A.R. 2002: Dry season survival, diapause duration and timing of diapause termination in the millet stem borer, Coniesta ignefusalis (Lepidoptera: Pyralidae) in Northern Ghana. Int. J. Pest Manage. 48: $33-37$.

Tauber M.J., Taurber C.A. \& Masaki S. 1986: Seasonal Adaptations of Insects. Oxford Univ. Press, New York, Oxford, 411 pp.

Tauber M.J., Tauber C.A. \& Nyrop J.P. 1994: Soil moisture and postdormancy emergence of Colorado potato beetle (Coleoptera: Chrysomelidae): Descriptive model and field emergence patterns. Environ. Entomol. 23: 1485-1496.

Tauber M.J., Tauber C.A., Nyrop J.P. \& Villani M.G. 1998: Moisture, a vital but neglected factor in the seasonal ecology of insects: Hypotheses and tests of mechanisms. Environ. Entomol. 27: 523-530

TopP W. 1986: Imaginal aestivation in the rove beetle species Omalium rivulare (Coleoptera: Staphylinidae). Entomol. Gener. 12: 51-55.

TSUKADA M. 1999: Interpopulation variation of hibernal-aestival diapause in the egg parasitoid wasp Anagrus takeyanus: adaptation to seasonal host-plant alternation of the tingid, Stephanitis takeyai. Entomol. Exp. Appl. 92: 37-43.

WARDHAUGH K.G. 1988: Diapause strategies in the Australian plague locust (Chortoicetes terminifera). In: Taylor F. \& Karban R. (eds): The Evolution of Insect Life Cycles. Springer, New York, pp. 89-104.

WITT A.B.R. \& EDWARDS P.B. 2002: Aspects of the biology, distribution and host range of Crioceris sp. (Col.: Chrysomelidae: Criocerinae), a potential biological agent for Asparagus asparagoides in Australia. Biol. Contr. 23: 56-63.

ZASLAVSKY V.A. 1978: Inductive and spontaneous processes in insect photoperiodism. Tr. Zool. Inst. Leningrad 69: 5-61. [in Russian]

Received November 15,2002; revised April 3, 2003; accepted April 3, 2003 